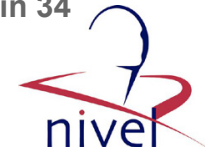

\begin{tabular}{|l|l|}
\hline $\begin{array}{l}\text { Postprint } \\
\text { Version }\end{array}$ & 1.0 \\
\hline Journal website & http://linkinghub.elsevier.com/retrieve/pii/S0168-8510(15)00192-X \\
\hline Pubmed link & $\underline{\text { http://www.ncbi.nlm.nih.gov/pubmed/26319096 }}$ \\
\hline DOI & $10.1016 /$ j.healthpol.2015.08.005 \\
\hline
\end{tabular}

This is a NIVEL certified Post Print, more info at http://www.nivel.eu

\title{
Primary care practice composition in 34 countries
}

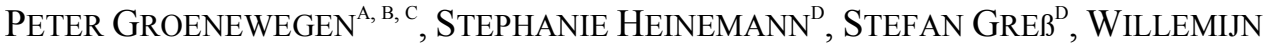 \\ SCHÄFER ${ }^{\mathrm{A}}$ \\ ${ }^{a}$ NIVEL - Netherlands Institute for Health Services Research, PO Box 1568, 3500 BN \\ Utrecht, The Netherlands \\ ${ }^{\mathrm{b}}$ Utrecht University, Department of Human Geography, Utrecht, The Netherlands \\ c Utrecht University, Department of Sociology, Utrecht, The Netherlands \\ ${ }^{d}$ Hochschule Fulda - University of Applied Sciences, Department of Health Sciences, \\ Leipziger Straße 123, 36037 Fulda, Germany
}

\begin{abstract}
Health care needs in the population change through ageing and increasing multimorbidity. Primary health care might accommodate to this through the composition of practices in terms of the professionals working in them. The aim of this article is to describe the composition of primary care practices in 34 countries and to analyse its relationship to practice circumstances and the organization of the primary care system. The data were collected through a survey among samples of general practitioners $(n=7183)$ in 34 countries. In some countries, primary care is mainly provided in single-handed practices. Other countries which have larger practices with multiple professional groups. There is no overall relationship between the professional groups in the practice and practice location. Practices that are located further from other primary care practices have more different professions. Practices with a more than average share of socially disadvantaged people and/or ethnic minorities have more different professions. In countries with a stronger pro-primary care workforce development and more comprehensive primary care delivery the number of different professions is higher. In conclusion, primary care practice composition varies strongly. The organizational scale of primary care is largely country dependent, but this is only partly explained by system characteristics.
\end{abstract}

\section{INTRODUCTION}

In this article we describe and analyse the composition of primary care practices in terms of the different professions that work together in 34, mainly European, countries. We do this against the background of the challenges posed by changing needs of the population, the organization of primary care and insights from the literature on human resource policies in health care. 
Primary care is the first point of contact in health care where people can present their health problems. Health care systems - and in particular primary care - face the challenges of responding to changing health needs in the population. Health problems are increasingly determined by multiple chronic diseases or multimorbity, partly as a result of the ageing of the population [1] and [2]. Multimorbidity is more than the sum of separate chronic diseases and requires a comprehensive approach to health problems and social problems. As a result of socio-economic health differences, disadvantaged groups in society - in terms of income, education and minority status - show higher levels of health needs. Changing epidemiological and social patterns require a supply of services and mix of skills able to deal with the health needs of the population, making the composition of the primary care practice a focal point for health human resource policy. Starfield [3] has characterized primary care as generalist care, which is stronger when it is more context and community oriented, and provides continuous, comprehensive and coordinated care. [4]. There is a large variation in the organization of primary care between countries [5] and [6]. General practitioners (GPs) are generally seen as the core specialism in primary care [7]. Their position differs between health care systems, depending upon whether or not patients have a free choice of physician or not. In more than half of the countries in our study (56\%) patients are required to go to a specific GP where they are registered for primary care. In this kind of system, GPs act as gatekeeper to specialized and/or hospital care [4]. There is large variation in GP specialty training. Not only the length of GP training, but also the content and place of training vary. In some countries (e.g. Austria and Greece) GPs are trained largely within the hospital setting. There is much less consensus about the need to involve other professional groups than GPs in primary care, but several sources provide a 'long-list' of professions working in primary care practices in different countries [8] and [9]. Primary care practices differ, therefore, in size and composition of the practice team in terms of the different professions involved. The smallest units will consist of only one GP; larger units may include supporting secretarial or nursing staff, specialized nurses, and additional professions.

Empirical research into staffing patterns in primary care is scarce. Aita et al. [10] studied community family medicine practices in Nebraska at the turn of the century and concluded that most practices used non-nursing staff as their predominant support staff. In the meantime, much has changed as witnessed by the extensive literature on the medical homes movement in the USA [11]. Part of this literature is related to staffing requirements [12] and [13].

Practice composition is an important issue from the point of view of expected shortages of health care personnel, especially physicians [14] and [15]. Particularly in countries with low population density, there are additional problems with attracting and retaining health care staff in rural areas [16]. Consequently, there will be differences in practice staff composition within countries, related to local needs and circumstances.

There are projected primary care workforce shortages. Various countries have or expect a lack of qualified GPs [17], especially due to ageing GPs [4, see Chapter 2]. Shortages of primary care and community nurses are also projected [18]. In addition to shortages, there are imbalances in the numbers of GPs, medical specialists and nurses, as for example in Greece [19]. There is an increasing body of literature on the related issue of substitution of GP care by nurses, nurse practitioners and physician 
assistants, suggesting that quality of care is the same or better and costs lower [20], [21] and [22]. However, actual substitution of tasks is generally low, as additional availability of nurses in primary care leads to an extension of service provision rather than less work for GPs [23].

Our description and analysis of practice composition in primary care can be seen against the background of these and related debates about health human resource policy. Health human resource policy 'includes ... governing, managing, planning, and monitoring the professional workforce at regional, national, and supranational levels' [24, p. 290]. At the national level monitoring and planning is still largely based on population to GP ratios [25]. Ratios have also been used in planning and staffing services for physicians and nurses, but less information is available for other professions [26], such as physiotherapists [27]. However, in view of the changing health needs of the population and the potential shortages and imbalances of health personnel, the required mix of professions and skills in primary care have become much more important.

Against this background, we will answer the following questions:

-How are primary care practices composed in terms of available professions?

-Is there a relationship between the composition of primary care practices and local circumstances, such as the location of practices and the composition of their patient population?

-Is there a relationship between the composition of primary care practices and the strength of primary care in a country?

\section{DATA AND METHODS}

The data on primary care practice composition was collected in the EU co-funded QUALICOPC study (see Box 1) [28]. We use information from the survey among GPs in 34 countries, three of which are outside Europe and five European but not EU Member States. 7183 GPs participated in the survey; the lowest number in Malta (70 respondents) and the highest number in Canada (535 respondents; see additional file 1). The development of the questionnaire and the data collection have been described elsewhere [29] and [30].

\section{[BOX 1]}

The first research question has been answered by a descriptive analysis of the answers to the survey question: 'Which of the following professions are working in your practice/centre?' The GPs selected from a list of 12 professional groups which ones were working in their practice. Hence, in all practices at least one or more GPs were working. For the descriptive analysis on all countries we have weighted the data attaching the same weight to each country, irrespective of differences in the number of respondents in each country.

The second and third research questions were answered by a multilevel linear regression analysis with countries as the higher level and GPs as the lower level. The dependent variable was the number of other professions available in the primary care practice, apart from GPs/FPs. This is a count variable with a rather skewed distribution, which gave us the choice between a Poisson regression and normalization of the dependent variable in order to be able to perform a linear regression. We have chosen the second option and normalized the dependent variable into $0,1,2,3,4$ and 5, 6 and 7 and 8 and more other professions. 
For the second research question, we used the location and the composition of the practice as independent variables. The location of the practice is described in terms of urbanity (in three categories: urban, suburban and small towns, rural or mixed urban-rural), the distance to the nearest other primary care practice (in the same building or at less than $10 \mathrm{~km}$ distance vs. more than $10 \mathrm{~km}$ distance) and the distance to the nearest secondary care services (same categories). The composition of the practice population was assessed in terms of the deviation from the national average of the share of elderly, socially disadvantaged people and people from ethnic minorities (answering categories above average, average and below average). These values were self-reported by the responding GPs. Since there were some missing values to these three questions (between 4 and $8 \%$ ), we used a dummy variable for the missing values to prevent losing observations (no significant effects, not in table). For the third research question we added primary care system characteristics to the multilevel linear regression model, including the local circumstances variables. To describe the primary care system, we used characteristics which were developed and collected in the Primary Health Care Activity Monitor Europe (PHAMEU) study [4] and [31]. System characteristics were added one by one to prevent overdetermination of the model due to the relatively small number of countries. We used the overall structure of primary care and its constituting dimensions: governance, economic conditions and workforce development, as well as the four process related dimensions of continuity, comprehensiveness, access and coordination of primary care. We estimated separate multilevel regression models for each system characteristic to prevent over-determination. All analyses were performed using Stata.

\section{RESULTS}

\subsection{Composition of primary care practices}

The size of primary care practices varies between countries and so does the composition of professions. In some countries, GPs work predominantly in small, often single-handed practices, while the modal general practice in other countries is part of a large health centre. The median number of other professions apart from GPs is zero in Belgium (see Fig. 1). This means that in the sample for this country, half of the GPs work just by themselves, even without a practice secretary. Other countries with very small practices in terms of number of professions are Austria, Germany, Luxemburg, Switzerland and Italy in Western Europe and Bulgaria, Czech Republic, Hungary, Romania and the FYR Macedonia in South-Eastern Europe. The largest number of professions was found in Lithuania (8 other professions), Finland (7), Cyprus and Spain (6) and Iceland, Sweden and England (with 5 other professions).

\section{[FIGURE 1]}

We do not know the size of the practice in terms of the number of professionals. We have only asked whether or not the other profession is working in the practice, but not the number in each professional group. For GPs, however, the survey included a question about their number in the practice. The number of GPs in a practice and the number of other professions shows a significant correlation of $0.42(p<0.01)$. This shows that practices with more professions are most probably also larger practices in terms of total personnel. 
Table 1 shows the type of professions working in primary care practices in the 34 countries. In practices with one extra profession, this is either a practice nurse or a receptionist/medical secretary. Practices with two extra professions typically have both a practice nurse and a receptionist/medical secretary. After that, patterns become more varied. Around a quarter of practices with three extra professions have, besides a practice nurse and a receptionist/medical secretary, a community/home care nurse or a manager. With four extra professions, they are joined by a midwife in more than $30 \%$ of practices. More than a quarter of practices with five extra professions have an assistant for laboratory work, a dentist, a physiotherapist, a pharmacist or a social worker in the practice.

\section{[TABLE 1]}

This is the pattern over all practices in all 34 countries. Behind this are strong differences between countries. If there is one extra profession apart from GP, the general pattern is that the former communist countries have a practice nurse and the other countries a receptionist/medical secretary (Table 2). There are a few exceptions to this: Danish practices with one extra profession have equal proportions with a practice nurse and with a receptionist/medical secretary; practices in Finland, Greece and Turkey with one extra profession typically have a practice nurse.

\section{[TABLE 2]}

When we come to practices with more extra professions it becomes more difficult to show the patterns in tables by country. However, we can still distillate some patterns with the situation of two extra professions (not shown in table). Twenty-five countries follow the general pattern that we found over all countries: they usually have a receptionist/medical secretary and a practice nurse. For two countries we do not have observations because their primary care practices in our sample commonly contain more than two extra professions (Sweden and Iceland). The other seven countries differ from the general picture in the following respects: Slovakian practices with two extra professions most often have (a) practice nurse(s) and a manager; Slovenian practices have practice nurses and community nurses; Swiss practices have a receptionist/medical secretary and a laboratory assistant; Turkish practices have a practice nurse and a midwife; Macedonian practices have a nurse practitioner and practice nurse. Belgian practices with more than two professions have a practice secretary and a dentist; Maltese practices have a practice secretary and a physiotherapist. However, practices with two extra professions are rare in Belgium, because there are very few larger practices, and in Malta, because there are very few smaller practices in terms of the number of professions.

It would take too much space to discuss all categories of the number of extra professions by country. Therefore, we will discuss the situation when a practice has extra professions. We have selected the countries with at least 10 practices with five extra professions; this reduces the number of countries to sixteen (see Table 3). These practices all have one or more practice nurses and/or practice secretaries. In addition we see that community/home care nurses are part in less than a quarter of the practices in England, the Netherlands, Australia and Canada. In all Anglo-Saxon countries in our study the management function is very frequent in these larger practices. A few countries report a large involvement of midwives: England, Greece, Iceland and Poland have midwives in more than three quarters of the practices with 
five extra professions. Laboratory assistants are less common as a profession: only in Greece, Iceland and Slovenia they are present in more than half of the in the primary care practices with five extra professions. With the professions that are in general less common in primary care practices, we also see more variations between countries. Dentists are an example; they are not part of the primary care teams in the practices with five or more professions in England, Iceland, the Netherlands and Sweden, while they are in more than half of these practices in Finland, Greece, Lithuania, Poland and Slovenia. We want to draw attention to the involvement of social workers in Portugal, Spain, Sweden and Canada, where they are part of the team in more than half of the practices with five extra professions.

\section{[TABLE 3]}

\subsection{Role of local circumstances}

The multilevel regression analysis reveals that more than half of the variation in practice size is at country level (see Table 4). The intraclass correlation is $58 \%$. There is no difference in the number of professions per practice between more urban and more rural areas. However, the relationship between practice location and number of professions varies between countries (significant slope variation); in some countries there is a relationship, but not in a consistent direction. Ten countries show a clear gradient from urban to rural, five of which have more different professions in urban areas and five countries (all of the Nordic countries) have more different professions in rural areas. Practices that are located further from other primary care practices have more different professions. Distance to secondary care is unrelated to the practice composition.

\section{[TABLE 4]}

The composition of the practice population is related to the number of professions per practice. Practices with a more than average share of socially disadvantaged people and those with a more than average share of ethnic minorities have more different professions. The share of elderly in the practice is not related to practice composition.

\subsection{Role of health care system characteristics}

The third research question addresses the relationship of the practice composition with characteristics of the primary care system. To answer this question, we have added the variables indicating the strength of primary care in each country one by one to the model with local circumstances (not in table). Eight system level variables were analysed: the primary care structure, governance, economic conditions, workforce development, continuity, comprehensiveness, coordination and access of primary care. In countries with a better developed primary care workforce $(p<0.05)$ and more comprehensive primary care processes $(p<0.10)$ there are more different professions in the primary care practices.

\section{DisCUSSION}

Our study has revealed a large variation in the practice composition of primary care. The largest share of this variation is at the country level. This indicates that practice size and composition is influenced by country level policies and/or historically developed patterns. There are large differences in the mix of professions working in 
primary care practices, together with GPs/FPs. There are countries with predominantly large practices with many different professions, such as Lithuania and Finland, alongside countries with small, single profession GP practices, such as Austria.

Our research shows that the same professionals might have a different role depending on the practices, but especially the health care systems they work in. Practice nurses in former communist countries have a role which seems to be equivalent to that of practice secretaries in Western European countries. They have been called 'writing nurses' as opposed to 'nursing nurses' in the past (Boerma, personal communication). Ladden et al. [32], in the US context, have pointed to different roles of nurses in terms of involvement in triage or in treatment. This might also be the case in the countries we studied. Nurses in some countries might have a predominantly triage function, while in others they are involved in multidisciplinary care for the chronically ill (e.g. the Netherlands where practice nurses have an important role in treating chronically ill and people with mental health problems). The location of practices is not related to the number of different professions in the primary care practice. There is no overall relation with the urban or rural location of the practice, although some countries show more different professions in urban areas and other countries the other way around. A large distance to other primary care practices coincides with more different professions; distance to secondary care services is unrelated.

Practice composition in terms of the patient groups being served is related to the number of professions. In practices with an above amount of socially disadvantaged people or people from ethnic minorities, the number of other professions in the practice is higher. This reflects the needs of the practice population; needs that might not be restricted to the medical field, but include needs in the area of nursing, psychosocial care and social work. Against this background of needs of the practice population, it is remarkable that a higher than average share of elderly in the population does not coincide with more professions in the practice. In some countries with mainly mono-disciplinary practices, multi-disciplinary health centres originated from idealistic movements; they are often located in urban disadvantaged areas (see the example of a community health centre in Ref. [9]).

We have also explored the relationship between the number of different professions in the primary care practice and characteristics of the system of primary care. Two primary care system characteristics turned out to be associated with the number of different professions in primary care practices, the structural dimension of workforce development and the process dimension of comprehensiveness. The PHAMEU workforce dimension consists of indicators that mainly relate to the position of GPs and nurses [4]. A large number of different professions in primary care practices is not possible without a well-developed workforce in primary care. The PHAMEU process dimension of comprehensiveness measures the activities in primary care, such as the range of curative and preventive services. The range of services can be broader with more professional groups working in primary care practices/centres. More surprising is the absence of an association with the PHAMEU dimension of coordination of care. This is also the dimension that includes whether GPs have a gatekeeping function. Working in a practice with several different professions could be expected to improve the coordination of care for patients in comparison to separate practices dealing with an aspect of the patient's care (physiotherapy, social 
care, midwifery, etc.). International variation in the organizational scale of primary care is probably related to the history of the health care system, with in general more different professions in countries with a national health system, e.g. Spain and England. Some of the transitional countries still have the large policlinics of their past health care system. Also the way primary care is funded may play a role. A strength of our study is that it contains a relatively large number of countries and many primary care practices. This made it possible to distinguish between the practice level and the country level and to look at the differences within countries between rural and urban areas.

Our study also has limitations. It should be noted that the associations we found are no more than associations and cannot be interpreted causally. The survey only included information on the different professions and not on the number of professionals per group. We also have no information on the actual cooperation between the professionals working in the same practice, nor do we have information about network types of cooperation between primary care professions that are not part of the same practice. Actual cooperation determines the added value of having different professions within the same practice. The data were collected through a survey with a variable - and on the whole rather low - participation rate. The median participation rate was $30 \%$. The response rate was most probably influenced by the fact that participating GPs were required to allow fieldworkers into their practices to recruit ten consecutive patients to fill in a questionnaire after their consultation. There might be a bias towards larger practices. Using a survey approach in international comparative research assumes that GPs who fill in the questionnaires mean the same thing by the same words [33]. The data, therefore, reflect the perceptions of the GPs; there may be discrepancies between what the responding GPs saw as professional groups in their practice or centre and formal employment relations to the practice or centre. Although the translation procedure was careful, using forward-backward translations, some terms may have a different connotation from one country to another. This is especially a problem with the different types of nurses [34].

\section{CONCLUSION}

This article has shown the strong variation in primary care practice composition in terms of the professional groups working in them. The organizational scale of primary care is largely country dependent, but this is only partly explained by system characteristics. An important issue is whether the different health care systems are prepared to face the challenges that we mentioned in the introduction. What mix of professions is needed in primary care to address the challenge of changing morbidity patterns and an ageing population? We did not study the relationship between differences in staffing mix between practices/countries and the efficiency or health outcomes in primary care. The relationships between staffing mix in primary care on the one hand and efficiency and health outcomes on the other hand are still underresearched [35]. Health human resource policies often only focus on physicians. There is a need for integrated health human resource policies that include other relevant professional groups, not only in health care but also in social care [26] and [36]. At local and regional level, population health care needs should be connected to the required mix of professionals and skills [37] and [38]. 
Groenewegen, P., Heinemann, S., Greß, S., Schäfer, W. Primary care team composition in 34 countries. Health Policy: 2015, 119(12), 1576-1583

\section{REFERENCES}

[1] Boeckxstaens P, Peersman W, Goubin G, Ghali S, De Maeseneer J,Brusselle G, et al. A practice-based analysis of combinations of dis-eases in patients aged 65 or older in primary care. BMC FamilyPractice 2014, September;15:159.

[2] Muth C1, van den Akker M, Blom JW, Mallen CD, Rochon J, SchellevisFG, et al. The Ariadne principles: how to handle multimorbidity inprimary care consultations. BMC Medicine 2014;12:223.

[3] Starfield B. Is primary care essential? The Lancet 1994;344:1129-33.

[4] Kringos DS, Boerma WGW, Hutchinson A, Saltman RB, editors. Build-ing primary care in a changing Europe. European observatory onhealth systems and policies. Observatory studies series, vol. 38. 2015.

[5] Gauld R, Blank R, Burgers J, Cohen AB, Dobrow M, Ikegami N, et al. Theworld health report 2008 - Primary healthcare: how wide is the gapbetween its agenda and implementation in 12 high-income healthsystems. Healthcare Policy 2012;7:38-58.

[6] Kringos D, Boerma W, Bourgueil Y, Cartier T, Dedeu T, Hasvold T, et al.The strength of primary care in Europe: an international compara-tive study. British Journal of General Practice 2013;63(616):e742-50,http://dx.doi.org/10.3399/bjgp13X674422.

[7] Saltman R, Rico A, Boerma W, editors. Primary care in the driver'sseat: organisational reform in European primary care. Maidenhead:Open University Press; 2006.

[8] Health Council. European primary care. The Hague: Health Councilof the Netherlands; 2004.

[9] EXPH (EXpert Panel on effective ways of investing in Health). Reporton definition of a frame of reference in relation to primary care witha special emphasis on financing systems and referral systems. Brus-sels: European Union; 2014, July.

[10] Aita V, Dodendorf DM, Lebsack JA, Tallia AF, Crabtree BF. Patientcare staffing patterns and roles in community-based family practices.Journal of Family Practice 2001;50(10):889.

[11] Takach M. About half of the states are implementing patient-centered medical homes for their Medicaid populations. HealthAffairs (Millwood) 2012;31(11):2432-40.

[12] Patel MS, Arron MJ, Sinsky TA, Green EH, Baker DW, Bowen JL, et al.Estimating the staffing infrastructure for a patient-centered medicalhome. American Journal of Managed Care 2013;19(6):509-16.

[13] Peikes DN, Reid RJ, Day TJ, Cornwell DDF, Dale SB, Baron RJ, et al.Staffing patterns of primary care practices in the comprehensiveprimary care initiative. Annals of Family Medicine 2014;14:2-149,http://dx.doi.org/10.1370/afm.1626.

[14] OECD. The looming crisis in the healthcare workforce. How can OCEDcountries respond? Paris: OECD Publishing; 2008.

[15] Bodenheimer TS, Smith MD. Primary care: proposed solutions to thephysician shortage without training more physicians. Health Affairs(Millwood) 2013;32(11):1881-6.

[16] Crettenden IF, McCarty MV, Fenech BJ, Heywood T, Taitz MC, TudmanS. How evidence-based workforce planning in Australia is informingpolicy development in the retention and distribution of the healthworkforce. Human Resources for Health 2014;12:7.

[17] Teljeur C, Thomas S, O'Kelly FD, O'Dowd T. General practitioner work-force planning: assessment of four policy directions. BMC HealthServices Research 2010;10:148.

[18] Storey C1, Ford J, Cheater F, Hurst K, Leese B. Nurses working inprimary and community care settings in England: problems andchallenges in identifying numbers. Journal of Nursing Management2007;15(8):847-52.

[19] Groenewegen PP, Jurgutis A. A future for primary care for the Greekpopulation. Quality in Primary Care 2013;21(6):369-78.

[20] Laurant M, Reeves D, Hermens R, Braspenning J, Grol R, Sibbald B.Substitution of doctors by nurses in primary care. Cochrane Databaseof Systematic Reviews 2005;18(2). CD001271.

[21] Keleher H, Parker R, Abdulwadud O, Francis K. Systematic review ofthe effectiveness of primary care nursing. International Journal ofNursing Practice 2009;15:16-24.

[22] Gielen SC, Dekker J, Francke AL, Mistiaen P, Kroezen M. The effectsof nurse prescribing: a systematic review. International Journal ofNursing Studies 2014;51(7):104861.

[23] Richardson G, Maynard A, Cullum N, Kindig D. Skill mix changes:substitution or service development? Health Policy 1998;45:119-32. 
[24] Kuhlmann E, Groenewegen PP, Batenburg R, Larsen C. Health humanresources policy in Europe. In: Kuhlmann E, Blank RH, BourgeaultIL, Wendt C, editors. The Palgrave international handbook of healthcare policy and governance. Basingstoke: Palgrave Macmillan; 2015.p. 289-307.

[25] Martix insight EU level collaboration on forecasting health work-force needs, workforce planning and health workforce trends: afeasibility study. European Commission; 2012 http://ec.europa.eu/health/workforce/docs/healthworkforce study 2012 report en.pdf

[26] Dubois C-A, Singh D. From staff-mix to skill-mix and beyond: towardsa systemic approach to health workforce management. HumanResources for Health 2009;7:87.

[27] Cartmill L, Comans TA, Clark MJ, Ash S, Sheppard L. Using staffingratios for workforce planning: evidence on nine allied health profes-sions. Human Resources for Health 2012;10:2.

[28] Schäfer WL, Boerma WG, Kringos DS, De Maeseneer J, Gress S, Heinemann S, et al. QUALICOPC, a multi-country study evaluatingquality, costs and equity in primary care. BMC Family Practice 2011, October;12:115.

[29] Schäfer WL, Boerma WG, Kringos DS, De Ryck E, Greß S, HeinemannS, et al. Measures of quality, costs and equity in primary health care:instruments developed to analyse and compare primary care in 35countries. Quality in Primary Care 2013;21(2):6779.

[30] Groenewegen PP, Gre _ S, Schäfer W. Participation rates of GPs; 2015 [submitted for publication].

[31] Kringos DS, Boerma WG, Bourgueil Y, Cartier T, Hasvold T, Hutchin-son A, et al. The European primary care monitor: structure, processand outcome indicators. BMC Family Practice 2010;11:81.

[32] Ladden MD, Bodenheimer T, Fishman NW, Flinter M, Hsu C, Parch-man M, et al. The emerging primary care workforce: preliminaryobservations from the primary care team: learning from effec-tive ambulatory practices project. Academic Medicine 2013;88(12):1830-4.

[33] Davidov E, Meuleman B, Cieciuch J, Schmidt P, Billiet J. Measurementequivalence in cross-national research. Annual Review of Sociology2014;40:55-75.

[34] Büscher A, Sivertsen B, White J. Nurses and midwives a forcefor health. Survey on the situation of nursing and midwiferyin the member states of the European region of the worldhealth organization 2009. Copenhagen: World Health Organization;2010.

[35] Fulton BD, Scheffler RM, Sparkes SP, Yoonkyung Auh E, Vujicic M,Soucat A. Health workforce skill mix and task shifting in low incomecountries: a review of recent evidence. Human Resources for Health2011;9:1.

[36] Kuhlmann E, Batenburg R, Groenewegen PP, Larsen C. Bringing aEuropean perspective to the health human resources debate: a scop-ing study. Health Policy 2013;110(1):6-13.

[37] de Graaf-Ruizendaal WA, de Bakker DH. The construction of a deci-sion tool to analyselocal demand and local supply for GP careusing a synthetic estimation model. Human Resources for Health2013;11:55.

[38] von Eitzen-Strassel J, Vrijhoef HJM, Derckx EWCC, de Bakker DH. Per-sonnel planning in general practices: development and testing ofa skill mix analysis method. Human Resources for Health 2014;12:53. 


\section{Box 1: The QUALICOPC study.}

The QUALICOPC study was co-funded by the European Commission under the so-called 'Seventh Framework Programme', and was carried out by a consortium of six research institutes from Belgium, Germany, Italy, the Netherlands and Slovenia. Data were collected in 31 European countries (26 EU countries, Iceland, Norway, Turkey, Switzerland and Macedonia). Furthermore, research units from Australia, Canada and New Zealand have joined the study. Data collection focused on three levels: the health care system, the GP practice and patients. Data on the health care system are derived from the Primary Health Care Activity Monitor Europe (PHAMEU). New information was collected through linked surveys among GPs (seen as the main providers of primary care), their patients and fieldworkers visiting GP practices. Answers to the questionnaires provide insight into the professional behaviour of GPs and the experiences of patients. In each country, the response target was 220 GPs (except for very small countries) and ten patients per GP. The questionnaires were translated in the national languages of the included countries via an official forward- and back-translation procedure and in some languages of large ethnic minority groups. 


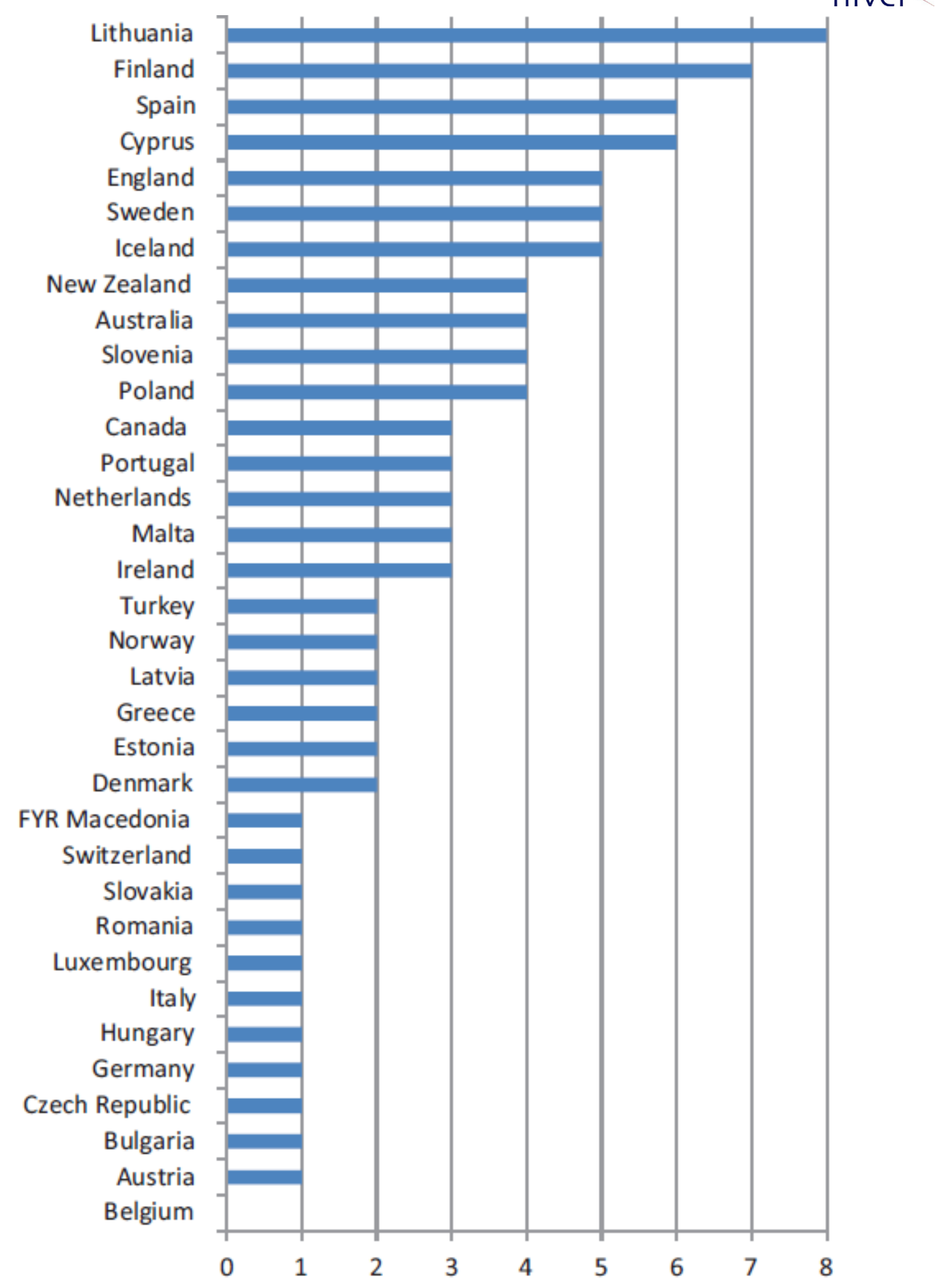

Fig. 1. Median number of extra professions in the practice (apart from GPs) in 34 countries. 
Groenewegen, P., Heinemann, S., Greß, S., Schäfer, W. Primary care team composition in 34 countries. Health Policy: 2015, 119(12), 1576-1583

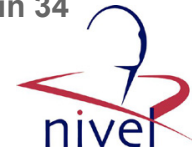

Table 1

Percentages of each profession in practices with $1,2, \ldots, 5$ extra professions (weighted analysis).

\begin{tabular}{|c|c|c|c|c|c|c|}
\hline Professional group & If 1 extra profession & If 2 & If 3 & If 4 & If 5 & Total of all practices \\
\hline Practice nurse & $49.2 \%$ & $78.4 \%$ & $88.6 \%$ & $100.0 \%$ & $100.0 \%$ & $73.9 \%$ \\
\hline Receptionist/medical secretary & $45.0 \%$ & $69.6 \%$ & $82.5 \%$ & $100.0 \%$ & $100.0 \%$ & $69.8 \%$ \\
\hline Community/home care nurse & $0.5 \%$ & $6.8 \%$ & $24.0 \%$ & $48.1 \%$ & $67.6 \%$ & $27.5 \%$ \\
\hline Manager & $0.1 \%$ & $5.8 \%$ & $27.7 \%$ & $43.8 \%$ & $50.2 \%$ & $20.9 \%$ \\
\hline Midwife & $0.3 \%$ & $7.8 \%$ & $14.4 \%$ & $31.2 \%$ & $47.6 \%$ & $18.7 \%$ \\
\hline Laboratory assistant & $0.5 \%$ & $8.0 \%$ & $15.1 \%$ & $16.0 \%$ & $38.2 \%$ & $17.4 \%$ \\
\hline Physiotherapist & $0.3 \%$ & $3.9 \%$ & $7.4 \%$ & $23.4 \%$ & $32.7 \%$ & $16.4 \%$ \\
\hline Dentist & $0.1 \%$ & $1.8 \%$ & $5.1 \%$ & $15.6 \%$ & $28.8 \%$ & $14.9 \%$ \\
\hline Nurse practitioner & $5.1 \%$ & $8.4 \%$ & $10.1 \%$ & $12.6 \%$ & $17.5 \%$ & $13.7 \%$ \\
\hline Social worker & $0.2 \%$ & $0.7 \%$ & $6.7 \%$ & $17.4 \%$ & $30.5 \%$ & $13.5 \%$ \\
\hline Pharmacist & $0.5 \%$ & $2.3 \%$ & $5.2 \%$ & $15.4 \%$ & $26.5 \%$ & $11.5 \%$ \\
\hline Psychiatric nurse & $0.0 \%$ & $0.3 \%$ & $4.8 \%$ & $10.9 \%$ & $14.3 \%$ & $10.9 \%$ \\
\hline Total number of practices & 2140 & 1307 & 898 & 605 & 522 & 7052 \\
\hline
\end{tabular}

Table 2

Practice composition of practices with one extra profession in percentages of the number of practices with 1 extra profession by country. ${ }^{\mathrm{a}}$

\begin{tabular}{|c|c|c|c|}
\hline Country & $\begin{array}{l}\text { Practice nurse (\%) if there is } \\
\text { one profession }\end{array}$ & $\begin{array}{l}\text { Receptionist/medical secretary (\%) } \\
\text { if there is one profession }\end{array}$ & $\begin{array}{l}\% \text { of practices with } 1 \text { extra } \\
\text { profession }(n)\end{array}$ \\
\hline Austria & 4 & 95 & $64.3 \%(110)$ \\
\hline Belgium & 3 & 92 & $32.6 \%(131)$ \\
\hline Bulgaria & 88 & 4 & $58.0 \%(127)$ \\
\hline Cyprus & 0 & 100 & $4.4 \%(4)$ \\
\hline Czech Republic & 99 & 1 & $86.2 \%(188)$ \\
\hline Denmark & 48 & 52 & $29.1 \%(61)$ \\
\hline Estonia & 100 & 0 & $40.3 \%(52)$ \\
\hline Finland & 100 & 0 & $0.4 \%(1)$ \\
\hline Germany & 2 & 98 & $75.6 \%(180)$ \\
\hline Greece & 72 & 13 & $18.6 \%(39)$ \\
\hline Hungary & 96 & 0 & $59.3 \%(128)$ \\
\hline Iceland & 0 & 100 & $2.5 \%(2)$ \\
\hline Ireland & 17 & 83 & $3.6 \%(6)$ \\
\hline Italy & 6 & 91 & $54.2 \%(109)$ \\
\hline Latvia & 81 & 3 & $17.0 \%(37)$ \\
\hline Lithuania & 0 & 0 & $1.8 \%(4)$ \\
\hline Luxemburg & 0 & 98 & $62.7 \%(47)$ \\
\hline FYR Macedonia & 42 & 0 & $71.0 \%(98)$ \\
\hline Malta & 9 & 55 & $19.0 \%(11)$ \\
\hline Netherlands & 17 & 83 & $2.6 \%(6)$ \\
\hline Norway & 2 & 98 & $48.5 \%(96)$ \\
\hline Poland & 63 & 25 & $3.6 \%(8)$ \\
\hline Romania & 99 & 1 & $75.8 \%(166)$ \\
\hline Spain & 100 & 0 & $0.5 \%(2)$ \\
\hline Slovakia & 93 & 0 & $84.0 \%(184)$ \\
\hline Slovenia & 100 & 0 & $18.0 \%(37)$ \\
\hline Switzerland & 0 & 97 & $76.7 \%(151)$ \\
\hline Turkey & 94 & 0 & $16.1 \%(48)$ \\
\hline Australia & 0 & 100 & $8 \%(12)$ \\
\hline Canada & 0 & 98 & $18.7 \%(94)$ \\
\hline New Zealand & 0 & 100 & $0.6 \%(1)$ \\
\hline
\end{tabular}

a The samples in England, Portugal and Sweden contained no practices with only one extra profession. 
Groenewegen, P., Heinemann, S., Greß, S., Schäfer, W. Primary care team composition in 34 countries. Health Policy: 2015, 119(12), 1576-1583

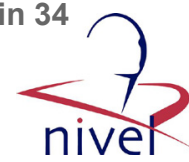

Table 3

Percentage of individual professional groups in practices with 5 extra professions by country.

\begin{tabular}{|c|c|c|c|c|c|c|c|c|c|c|c|c|}
\hline Country & $\begin{array}{l}\text { Practice } \\
\text { nurse }\end{array}$ & $\begin{array}{l}\text { Secretary } \\
\text { receptionist }\end{array}$ & $\begin{array}{l}\text { Comm./ } \\
\text { home } \\
\text { nurse }\end{array}$ & Manager & Midwife & $\begin{array}{l}\text { Lab } \\
\text { assistant }\end{array}$ & Dentist & Physiotherapist & $\begin{array}{l}\text { Social } \\
\text { worker }\end{array}$ & $\begin{array}{l}\text { Nurse } \\
\text { pract. }\end{array}$ & Pharmacist & $\begin{array}{l}\text { Psych } \\
\text { nurse }\end{array}$ \\
\hline Cyprus & 91 & 100 & 82 & 9 & 9 & 9 & 45 & 9 & 9 & 0 & 91 & 45 \\
\hline England & 98 & 98 & 22 & 100 & 80 & 12 & 0 & 18 & 0 & 57 & 12 & 4 \\
\hline Finland & 96 & 96 & 93 & 4 & 7 & 22 & 59 & 37 & 15 & 26 & 4 & 41 \\
\hline Greece & 85 & 74 & 26 & 41 & 78 & 70 & 78 & 0 & 19 & 19 & 7 & 4 \\
\hline Iceland & 100 & 100 & 100 & 11 & 100 & 71 & 0 & 0 & 14 & 4 & 0 & 0 \\
\hline Ireland & 94 & 100 & 28 & 83 & 22 & 6 & 39 & 50 & 17 & 6 & 39 & 17 \\
\hline Lithuania & 92 & 85 & 38 & 54 & 54 & 8 & 85 & 0 & 8 & 62 & 15 & 0 \\
\hline Netherlands & 95 & 100 & 14 & 29 & 33 & 24 & 0 & 67 & 24 & 5 & 67 & 43 \\
\hline Poland & 96 & 77 & 100 & 19 & 88 & 12 & 58 & 38 & 0 & 0 & 8 & 4 \\
\hline Portugal & 100 & 95 & 90 & 14 & 14 & 5 & 38 & 33 & 100 & 0 & 0 & 10 \\
\hline Spain & 95 & 89 & 94 & 4 & 54 & 29 & 21 & 11 & 84 & 19 & 0 & 0 \\
\hline Slovenia & 100 & 53 & 88 & 16 & 9 & 63 & 66 & 75 & 6 & 3 & 16 & 6 \\
\hline Sweden & 92 & 100 & 100 & 54 & 4 & 38 & 0 & 23 & 77 & 0 & 4 & 8 \\
\hline Australia & 100 & 100 & 17 & 96 & 17 & 46 & 17 & 50 & 0 & 13 & 30 & 22 \\
\hline Canada & 74 & 100 & 13 & 87 & 0 & 35 & 11 & 13 & 55 & 47 & 62 & 4 \\
\hline New Zealand & 100 & 100 & 27 & 82 & 23 & 27 & 14 & 32 & 14 & 23 & 50 & 9 \\
\hline
\end{tabular}

a Only for countries with more than 10 practices with 5 extra professions.

\section{Table 4}

Multilevel linear regression analysis of local circumstances on number of additional professions (34 countries, 6977 practices).

\begin{tabular}{lcc}
\hline & Null model & $\begin{array}{l}\text { Local } \\
\text { circumstances }\end{array}$ \\
\hline Intercept & $2.475(0.197)^{*}$ & $2.420(0.199)^{*}$ \\
Practice location: urban (ref) & & \\
$\quad$ Small towns/suburbs & $0.007(0.031)$ \\
Rural/mixed urban-rural & $0.052(0.036)$ \\
Distance to other GP practice & $0.096(0.046)^{*}$ \\
$>10 \mathrm{~km}$ & \\
Distance to secondary care & $-0.014(0.036)$ \\
$>10 \mathrm{~km}$ & \\
Share of elderly people in practice: average (ref) & \\
$\quad$ Below average & $0.023(0.036)$ \\
Above average & $0.004(0.027)$ \\
Share of disadvantaged in practice: average (ref) & \\
Below average & $-0.028(0.030)$ \\
Above average & $0.108(0.033)^{*}$ \\
Share of ethnic minorities in practice: average (ref) & \\
Below average & & $-0.003(0.030)$ \\
Above average & & $0.096(0.040)^{*}$ \\
Country variance & $1.316(0.321)^{*}$ & $1.303(0.317)^{*}$ \\
Practice variance & $0.938(0.016)^{*}$ & $0.933(0.016)^{*}$ \\
Intraclass correlation & 0.58 & 0.58 \\
\hline
\end{tabular}

$p<0.05$. 